Article

\title{
Traceability of Satsuma Mandarin (Citrus unshiu Marc.) Honey through Nectar/Honey-Sac/Honey Pathways of the Headspace, Volatiles, and Semi-Volatiles: Chemical Markers
}

\author{
Igor Jerković ${ }^{1, *}$, Saša Prđun ${ }^{2}$, Zvonimir Marijanović ${ }^{3}$, Marina Zekić ${ }^{1}$, Dragan Bubalo ${ }^{2}$, \\ Lidija Svečnjak ${ }^{2}$ and Carlo I. G. Tuberoso ${ }^{4}$ \\ 1 Department of Organic Chemistry, Faculty of Chemistry \& Technology, University of Split, \\ Ruđera Boškovića 35, HR-21000 Split, Croatia; zekic@ktf-split.hr \\ 2 Department of Fisheries, Apiculture and Special Zoology, Faculty of Agriculture, University of Zagreb, \\ Svetošimunska 25, HR-10000 Zagreb, Croatia; sprdjun@agr.hr (S.P.); dbubalo@agr.hr (D.B.); \\ lsvecnjak@agr.hr (L.S.) \\ 3 Department of Food Technology, Marko Marulić Polytechnic in Knin, Petra Krešimira IV 30, HR-22300 Knin, \\ Croatia; zmarijanovic@veleknin.hr \\ 4 Department of Life and Environmental Sciences, University of Cagliari, via Ospedale 72, IT-09124 Cagliari, \\ Italy; tuberoso@unica.it \\ * Correspondence: igor@ktf-split.hr; Tel.: +385-21-329-436
}

Academic Editor: Derek J. McPhee

Received: 29 August 2016; Accepted: 23 September 2016; Published: 29 September 2016

\begin{abstract}
Headspace solid-phase microextraction (HS-SPME) and ultrasonic solvent extraction (USE), followed by GC-MS/FID, were applied for monitoring the nectar (NE)/honey-sac (HoS)/honey (HO) pathways of the headspace, volatiles, and semi-volatiles. The major NE (4 varieties of Citrus unshiu) headspace compounds were linalool, $\alpha$-terpineol, $1 H$-indole, methyl anthranilate, and phenylacetonitrile. Corresponding extracts contained, among others, $1 H$-indole, methyl anthranilate, 1,3-dihydro-2H-indol-2-one and caffeine. The major HoS headspace compounds were linalool, $\alpha$-terpineol, 1,8-cineole, $1 H$-indole, methyl anthranilate, and cis-jasmone. Characteristic compounds from HoS extract were caffeine, $1 H$-indole, 1,3-dihydro- $2 H$-indol-2-one, methyl anthranilate, and phenylacetonitrile. However, $\mathrm{HO}$ headspace composition was significantly different in comparison to NE and HoS with respect to phenylacetaldehyde and linalool derivatives abundance that appeared as the consequence of the hive conditions and the bee enzyme activity. C. unshiu honey traceability is determined by chemical markers: phenylacetaldehyde, phenylacetonitrile, linalool and its derivatives, as well as $1 H$-indole, 1,3-dihydro- $2 H$-indol-2-one, and caffeine.
\end{abstract}

Keywords: Citrus unshiu Marc. honey; phenylacetaldehyde; phenylacetonitrile; linalool and its derivatives; $1 H$-indole; 1,3-dihydro-2H-indol-2-one; caffeine; HS-SPME; USE; GC-MS

\section{Introduction}

The most common and economically important varieties of Satsuma mandarin (Citrus unshiu Marc.) in Croatia (Neretva valley, Opuzen area) are Wakiyama, Chahara, Okitsu, Kawano Wase, Owari, Saigon, Kuno, Zorica, Ichumare, and Seto [1]. Around 2.5 million mandarin trees have been planted [1] in the Opuzen area (ca. $2500 \mathrm{ha}$ ) providing a good nectar source for unifloral honey production and potential for independent commercialization (not just as Citrus honey without distinction of the species). C. unshiu honey has not yet been characterized in detail.

Melissopalynological analysis, based on the identification and quantification of the pollen percentage by microscopic examination, has been accepted as the reference method to authenticate 
honey botanical origin [2]. However, pollen analysis is considered of little value for the Citrus genus as it is one of several honey types with underrepresented pollen [3,4]. Accordingly, C. unshiu honey characterisation is difficult with underrepresented pollen due to the specific plant physiology of particular mandarin cultivars (aborted anthers, sterile pollen grains, or partenocarpy). Therefore, there is a need for detailed chemical characterisation of $C$. unshiu honey and present research is focused on its volatile organic compounds (VOCs). The usefulness of VOC analysis in the determination of the honey botanical origin has been reported previously [5-7]. The aroma profile can be considered to be a "fingerprint" of unifloral honey directly related to the plant nectar [8].

Citrus honey has been often analysed without distinction between different species (C. sinensis L., C. deliciosa Ten., C. limon L., etc.) or, at best, as orange/lemon blossom honey. The extracts from Citrus honey contain linalool derivatives, such as (E)-2,6-dimethylocta-2,7-diene-1,6-diol, 2,6-dimethylocta-3,7-diene-2,6-diol or (Z)-2,6-dimethylocta-2,7-diene-1,6-diol [9]. Higher concentrations of linalool oxides and lilac aldehydes/alcohols were also found in the honey headspace [10-13]. $\alpha$-4-Dimethylcyclohex-3-ene-1-acetaldehyde was present in Greek Citrus honey [10]. Methyl anthranilate has been suggested as a Citrus honey floral marker [14]. Two isomers of sinensal, the volatile component of orange essential oil, were identified in Spanish Citrus honey [12]. The enantiomeric ratio between (3S)-linalool and (3R)-linalool in orange honey was about 13:87 similar as in orange flowers, and trans-(2R,5R)-linalool oxide with cis-(2S,5R)-linalool oxide prevailed [15]. The volatiles composition, physicochemical parameters, flavonoids and phenolic compounds were used as tools in the statistical analysis for the differentiation of lemon and orange honey $[16,17]$. A stepwise discriminant analysis using 37 volatiles and different parameters (diastase, conductivity, Pfund colour, and CIE L*a* ${ }^{*}$ ) provided the model for classification of the samples. A multivariate PLS2 analysis showed that lilac aldehydes and phenylacetaldehyde (all abundant in orange honey) were negatively correlated with four flavonoids (pinocembrin, chrysin, naringenin, and quercetin) and caffeic acid, all abundant in lemon honey. Moreover, the last five compounds were positively correlated with six alcohols, two ketones, acetaldehyde, and furanmethanol. In addition, caffeine is present in Citrus honey at about 1-10 mg/kg [18].

Basic physicochemical parameters of $C$. unshiu honey were determined in our previous research [19] with the following average values: water content $16.00 \%$, electrical conductivity $0.23 \mathrm{mS} \cdot \mathrm{cm}^{-1}$, fructose and glucose $77.33 \%$, saccharose $1.5 \%$, free acidity $15.10 \mathrm{mEq} \cdot \mathrm{kg}^{-1}$ and diastase activity 10.60 (DN). The present research emphases: (a) the headspace, volatile and semi-volatile nectar compounds from the varieties Zorica, Chahara, Kawano Wase, and Okitsu, from the honey-sac of the bees returning from C. unshiu pastures and corresponding honey; (b) GC-FID and GC-MS analysis of the headspace using headspace solid-phase microextraction (HS-SPME) and the volatiles and semi-volatiles after ultrasonic solvent extraction (USE); (c) methyl anthranilate, caffeine, and other compounds' abundances in the nectar/honey-sac/honey with respect to C. unshiu honey traceability; (d) the comparison of applied extraction methods with respect to obtained chemical profiles; and (e) qualitative comparison with available data on other Citrus honey VOCs.

\section{Results and Discussion}

This research has been designed to follow the nectar (NE)/honey-sac (HoS)/honey (HO) pathways of the headspace, volatiles, and semi-volatiles in order to characterize Satsuma mandarin (Citrus unshiu Marc.) honey. Two complementary methods for VOC isolation (without artefact generation) were applied: HS-SPME (with two fibres: divinylbenzene/carboxene/polydimethylsiloxane (DVB/CAR/PDMS) and polydimethylsiloxane/divinylbenzene (PDMS/DVB)) and USE (using two solvents: pentane/ $\mathrm{Et}_{2} \mathrm{O} 1: 2(v / v)$ and $\left.\mathrm{CH}_{2} \mathrm{Cl}_{2}\right)$. The applied chemical screening methodologies indicated striking differences in the obtained chemical profiles (depending on the volatility/solubility/sample). As was previously mentioned, the melissopalynological analysis cannot be used ambiguously to authenticate this honey. To ensure the unifloral honey origin, all of the samples were collected under controlled bee-hive locations in the area where C. unshiu predominantly 
grows. In investigated samples of the local beekeepers Satsuma mandarin pollen ranged from 1\%-10\%, and in other samples 3\%-41\%. The pollen grains from other nectar plant species in the samples were: Capsela bursa pastoris L., Asteraceae (Taraxacum form), Citrus sinensis L., Fabaceae spp., Rhamnus spp., Colutea arborescens L., Diplotaxis erucoides L., Centaurea spp. and Cerastium spp.

\subsection{The Nectars' Chemical Composition of the Headspace, Volatiles and Semi-Volatiles}

The major headspace compounds from all nectar varieties were nitrogen-containing compounds $1 \mathrm{H}$-indole $(7.3 \%-52.5 \% ; 12.2 \%-47.4 \%)$ and methyl anthranilate $(3.0 \%-8.5 \% ; 5.6 \%-19.8 \%)$, Table 1 . Higher percentages of $1 \mathrm{H}$-indole was found in NE Okithu and Zorica and methyl anthranilate in NE Kawano Wase. Those compounds derive from chorismate in the tryptophan biosynthetic pathway (Figure 1). The plant enzymes catalyse three subsequent steps [20]. PR-anthranilate transferase catalyses phosphoribosyl moiety transfer from phospho-ribosylpyrophosphate to anthranilate. In the next step, PR-anthranilate isomerase rearranges PR-anthranilate to 1-(O-carboxyphenylamino)-1-deoxyribulose-5-phosphate. Indole-3-glycerolphosphate synthase next forms an indole ring during the conversion of 1-(O-carboxyphenyIamino)-1-deoxyribulose-5-phosphate to indole-3-glycerolphosphate.

Table 1. The headspace chemical composition of the honey-sac (HoS) and nectars (NE) of different $C$. unshiu varieties determined by HS-SPME/GC-MS/FID analysis.

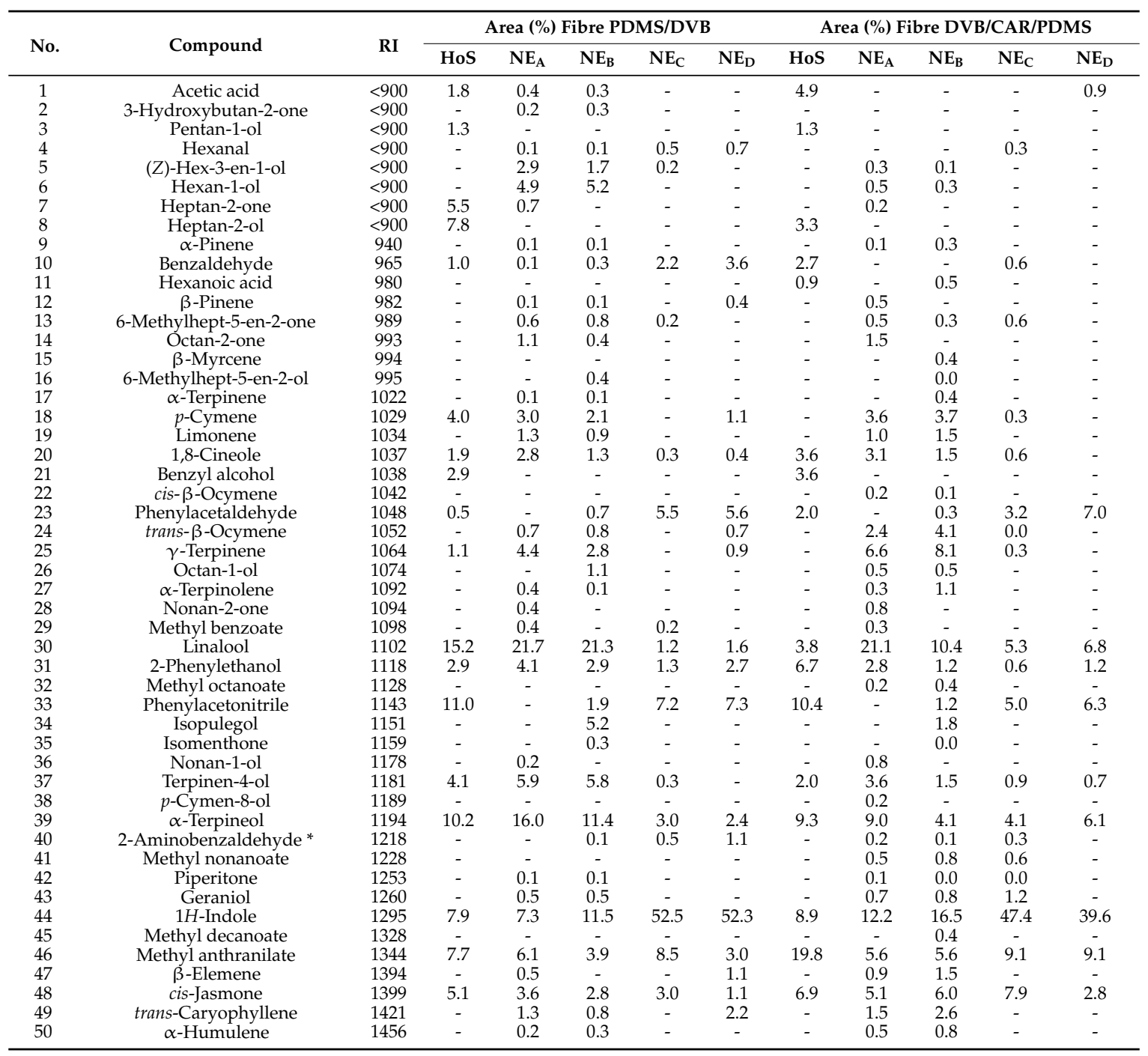


Table 1. Cont.

\begin{tabular}{|c|c|c|c|c|c|c|c|c|c|c|c|c|}
\hline \multirow{2}{*}{ No. } & \multirow{2}{*}{ Compound } & \multirow{2}{*}{ RI } & \multicolumn{5}{|c|}{ Area (\%) Fibre PDMS/DVB } & \multicolumn{5}{|c|}{ Area (\%) Fibre DVB/CAR/PDMS } \\
\hline & & & HoS & $\mathrm{NE}_{\mathrm{A}}$ & $\mathrm{NE}_{\mathrm{B}}$ & $\mathrm{NE}_{\mathrm{C}}$ & $\mathrm{NE}_{\mathrm{D}}$ & HoS & $\mathrm{NE}_{\mathrm{A}}$ & $\mathrm{NE}_{\mathrm{B}}$ & $\mathrm{NE}_{\mathrm{C}}$ & $\mathrm{NE}_{\mathrm{D}}$ \\
\hline 51 & $(E, Z)$ - $\alpha$-Farnesene & 1496 & - & - & - & - & - & - & 0.5 & 0.0 & - & - \\
\hline 52 & $(E, E)-\alpha$-Farnesene & 1503 & - & 0.4 & 0.1 & - & - & - & 2.0 & 2.6 & - & 0.7 \\
\hline 53 & Methyl dodecanoate & 1523 & - & - & - & - & - & - & 0.2 & - & - & 0.9 \\
\hline 54 & Caryophyllene oxide & 1584 & - & - & - & - & - & - & - & 0.7 & - & - \\
\hline 55 & Methyl tetradecanoate & 1727 & - & - & 0.3 & 0.5 & 1.1 & - & 0.9 & 2.2 & - & 1.6 \\
\hline 56 & Methyl hexadecanoate & 1929 & - & 0.4 & 0.9 & 1.3 & 2.7 & - & - & 5.5 & - & 6.1 \\
\hline
\end{tabular}

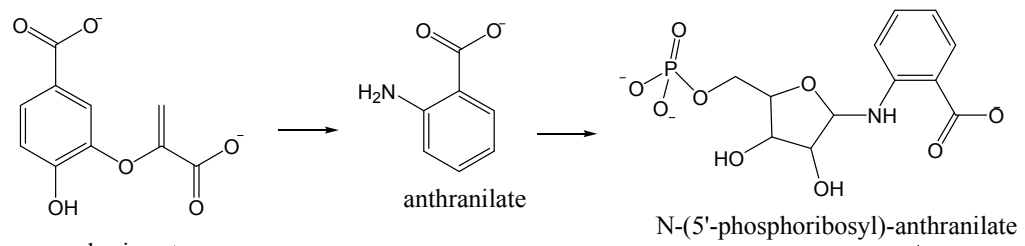
chorismate

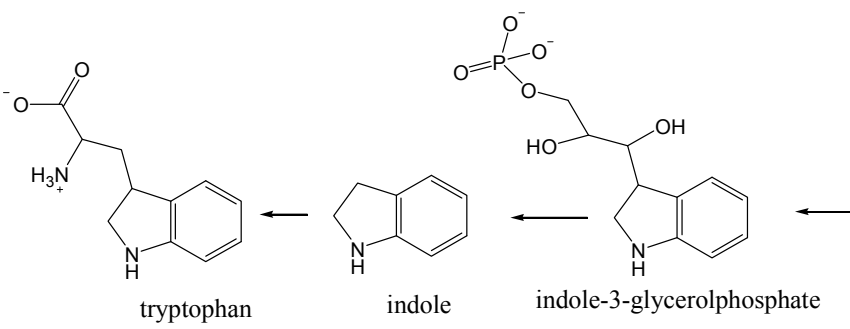<smiles>CC(=O)c1ccccc1N/C=C(\O)C(O)C(O)COP1(=O)OP(=O)(O)O1</smiles>

1-(O-carboxyphenylamino)1-deoxyribulose-5-phosphate

Figure 1. Tryptophan biosynthetic pathway.

The major oxygenated monoterpenes in NE headspace were linalool (1.2\%-21.7\%; 5.3\%-21.1\%) and $\alpha$-terpineol $(2.4 \%-16.0 \% ; 4.1 \%-9.3 \%)$. Their highest percentages were found in NE Kawano Wase and Chahara. Other abundant monoterpenes were terpinen-4-ol (0.0\%-5.9\%; $0.7 \%-3.6 \%)$, 1,8 -cineole $(0.4 \%-2.8 \% ; 0.0 \%-3.7 \%)$ and $\gamma$-terpinene $(0.0 \%-4.4 \% ; 0.0 \%-8.1 \%)$. All these compounds are biosynthetically related and derive from geranyl pyrophosphate. Other monoterpenes were occasionally found in several nectar types (Table 1). Only a few sesquiterpenes, pharnesyl pyrophosphate derivatives, were present with trans-caryophyllene $(0.0 \%-2.2 \% ; 0.0 \%-2.6 \%)$ as the major contributor.

cis-Jasmone (cis-3-methyl-2-(2-pentenyl)-cyclopent-2-en-1-one) was found (1.1\%-3.6\%; $2.8 \%-7.9 \%)$ in all NE. It is produced by the plants by an oxidative degradation of jasmonic acid (formed by lipoxygenase-catalyzed oxygenation of linolenic acid via 18-carbon cyclic fatty acid formed by the action of hydroperoxide cyclase, followed by reduction and $\beta$-oxidations), via 1,2-didehydrojasmonic acid [21]. Subsequent protonation of the carbonyl $O$-atom of 1,2-didehydrojasmonic acid is assumed to induce a Grob-type fragmentation of the molecule, yielding $\mathrm{CO}_{2}$ and cis-jasmone (Figure 2a).

Among benzene derivatives formed by the shikimate biosynthetic pathway, 2-phenylethanol $(1.3 \%-4.1 \% ; 0.6 \%-2.8 \%)$ and benzaldehyde $(0.1 \%-3.6 \% ; 0.0 \%-0.6 \%)$ were abundant with different distributions among $\mathrm{NE}_{\mathrm{A}}-\mathrm{NE}_{\mathrm{D}}$ (Table 1). Benzyl alcohol, phenylacetaldehyde (more abundant in $\mathrm{NE}$ Okitsu and Zorica) and methyl benzoate were also found. Phenylacetonitrile $(0.0 \%-7.3 \% ; 0.0 \%-6.3 \%)$ is another benzene derivative containing nitrogen. Its formation has been found in several secondary metabolic pathways initiating from phenylalanine in the plants [22]. Phenylalanine is first converted to $(E, Z)$-phenylacetaldoxime, which is then transformed to 2-hydroxy-2-phenylacetonitrile, probably via phenylacetonitrile formation as the intermediate (Figure $2 b$ ). 


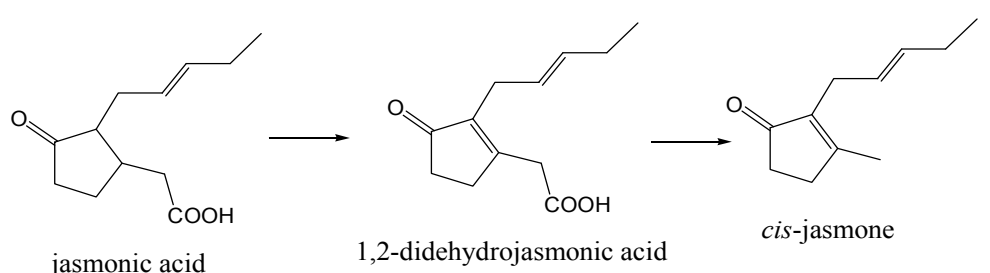

(a)<smiles>CCOC(=O)C(N)Cc1ccccc1</smiles>

phenylalanine<smiles>ON=CCc1ccccc1</smiles>

(E,Z)-phenylacetaldoxime

(b)

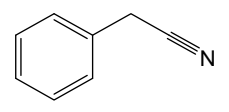

phenylaetonitrile

Figure 2. (a) Formation of cis-jasmone.; and (b) formation of phenylacetonitrile.

$\mathrm{NE}_{\mathrm{A}}-\mathrm{NE}_{\mathrm{D}}$ headspace also contained lower aliphatic compounds up to $\mathrm{C}_{10}$ (Table 1), most probably derived from fatty acid degradation. These compounds include alcohols (e.g., (Z)-hex-3-en-1-ol, pentan-1-ol or hexan-1-ol), ketones (e.g., heptan-2-one or octan-2-one), acids (acetic and hexanoic), and methyl esters (octanoate, nonanoate and decanoate).

Ultrasonic solvent extracts of $\mathrm{NE}_{\mathrm{A}}-\mathrm{NE}_{\mathrm{D}}$ were strikingly different from the headspace composition, containing less volatile compounds (Table 2). The major ones were (Z)-octadec-9-en-1-ol $(14.3 \%-52.3 \%)$, octadecan-1-ol $(5.3 \%-26.0 \%)$ and hexadecan-1-ol $(6.9 \%-16.5 \%)$. The headspace nitrogen-containing compounds were also identified by USE: $1 \mathrm{H}$-indole $(2.7 \%-10.3 \%)$ and methyl anthranilate $(0.9 \%-11.7 \%)$. However, new nitrogen compound appeared in the extracts, $1 H$-indole derivative-1,3-dihydro- $2 \mathrm{H}$-indol-2-one $(0.2 \%-18.1 \%)$. It is interesting to note that the Schiff base of 1,3-dihydro-2 $\mathrm{H}$-indol-2-one and its synthetic derivatives bearing a 1,3-dihydro-2 $\mathrm{H}$-indol-2-one nucleus were reported for antibacterial, antifungal, anti-HIV, and anticonvulsant activities and GAL3 receptor antagonists [23].

Table 2. The results of GC-FID and GC-MS analysis of the extracts from the honey-sac (HoS) and nectars (NE) obtained by USE.

\begin{tabular}{|c|c|c|c|c|c|c|c|}
\hline \multirow{2}{*}{ No. } & \multirow{2}{*}{ Compound } & \multirow{2}{*}{ RI } & \multicolumn{5}{|c|}{ Area $(\%)$} \\
\hline & & & HoS & $\mathrm{NE}_{\mathrm{A}}$ & $\mathrm{NE}_{\mathrm{B}}$ & $\mathrm{NE}_{\mathrm{C}}$ & $\mathrm{NE}_{\mathbf{D}}$ \\
\hline 1 & 2-Phenylethanol & 1118 & - & 1.9 & - & - & - \\
\hline 2 & Phenylacetic acid & 1262 & 3.0 & - & - & - & - \\
\hline 3 & $1 H$-Indole & 1295 & 1.6 & 6.8 & 2.7 & 10.3 & 6.4 \\
\hline 4 & Methyl anthranilate & 1344 & 1.4 & 11.7 & 0.9 & 1.4 & 1.2 \\
\hline 5 & 1-Hydroxylinalool ** & 1366 & 5.4 & - & - & - & - \\
\hline 6 & 1,3-Dihydro-2H-indol-2-one & 1471 & 6.4 & 18.1 & 0.2 & 3.1 & 0.8 \\
\hline 7 & Caffeine & 1842 & 11.5 & 8.9 & 1.1 & 4.3 & 2.1 \\
\hline 8 & Hexadecan-1-ol & 1882 & 11.6 & 6.9 & 10.7 & 15.7 & 16.5 \\
\hline 9 & Methyl hexadecanoate & 1929 & - & 4.3 & - & 13.7 & 0.0 \\
\hline 10 & (Z)-Octadec-9-en-1-ol & 2059 & 45.3 & 25.4 & 69.2 & 14.3 & 52.3 \\
\hline 11 & Octadecan-1-ol & 2084 & 8.6 & 6.1 & 5.3 & 26.0 & 12.7 \\
\hline
\end{tabular}

HoS = honey-sac, $\mathrm{NE}_{\mathrm{A}}=$ nectar Kawano Wase, $\mathrm{NE}_{\mathrm{B}}=$ nectar Chahara, $\mathrm{NE}_{\mathrm{C}}=$ nectar Okitsu, $\mathrm{NE}_{\mathrm{D}}=$ nectar Zorica, $\mathrm{RI}=$ retention indices on HP-5MS column, ${ }^{* *}=$ correct isomer is not identified.

Methylxanthine-derivative caffeine was found (1.1\%-8.9\%) in the extracts of $\mathrm{NE}_{\mathrm{A}}-\mathrm{NE} \mathrm{D}_{\mathrm{D}}$. Xanthine (3,7-dihydro- $1 H$-purine-2,6-dione) derivatives belong to purine alkaloids. The major pathway of caffeine biosynthesis is xanthosine $\rightarrow$ 7-methylxanthosine $\rightarrow$ 7-methylxanthine $\rightarrow$ theobromine $\rightarrow$ caffeine [24]. The presence of methyxanthine derivatives in the nectar and pollen of Coffea, Camellia, Theobroma, Herrania, Cola, Ilex, Paullinia, and Citrus spp. was previously determined by HPLC [18]. The nectar of $C$. paradise, C. maxima, and C. limon contained caffeine $\left(60-487 \mathrm{nmol} \cdot \mathrm{mL}^{-1}\right)$, theobromine 
$\left(0-22 \mathrm{nmol} \cdot \mathrm{mL}^{-1}\right)$, theophylline $\left(0-55 \mathrm{nmol} \cdot \mathrm{mL}^{-1}\right)$ and paraxanthine $\left(0-12 \mathrm{nmol} \cdot \mathrm{mL}^{-1}\right)$. It is difficult to compare the abundance of caffeine (Table 2) determined by USE/GC-MS/FID with the results of direct HPLC analysis, which is focused on the non-volatiles analysis.

Generally, Satsuma mandarin peel essential oil was characterized by a high percentage of limonene $(67.4 \%)$, followed by $\beta$-myrcene, car-3-ene, $\alpha$-pinene, $p$-cymene, $\beta$-pinene, sabinene, terpinolene, and $\alpha$-thujene [25]. The principal chemical constituents of $C$. unshiu flower essential oil included $\gamma$-terpinene $(24.7 \%), \beta$-pinene $(16.6 \%), o$-cymene $(11.5 \%)$, limonene $(5.7 \%), \beta$-ocimene $(5.6 \%)$ and $\alpha$-pinene (4.7\%) [25]. It is already known that the composition of the nectar and essential oil from the same plant is very different [26]. However, several common compounds were found in the flower essential oil and C. unshiu nectar headspace investigated herein, such as $\gamma$-terpinene, limonene, $\alpha$-pinene, and $\beta$-pinene.

\subsection{The Chemical Composition of the Content of Honey-Sac Headspace, Volatiles and Semi-Volatiles}

The gathered nectar is stocked in the honey-sac, which can contain up to $60 \mu \mathrm{L}$. The enzymes in the saliva start to degrade the nectar sucrose into glucose and fructose and cleave the glycosides. The content of the sacs of the bees caught at the entrance of the hive on their way back from C. unshiu nectar-gathering was investigated by HS-SPME/GC-MS/FID (Table 3) and USE/GC-MS/FID (Table 4). Dominant compounds were oxygenated monoterpenes, the major ones were linalool $(15.2 \% ; 3.8 \%)$, $\alpha$-terpineol $(10.2 \% ; 9.3 \%)$ and 1,8-cineole $(1.9 \% ; 3.6 \%)$, Table 3. Two nitrogen-containing compounds were found among the abundant compounds: $1 H$-indole $(7.9 \% ; 8.9 \%)$ and methyl anthranilate $(7.7 \% ; 19.8 \%)$. cis-Jasmone was also present $(5.1 \% ; 6.9 \%)$. The headspace benzene derivatives were mainly comprised of benzaldehyde $(1.0 \% ; 2.7 \%)$, benzyl alcohol $(2.9 \% ; 3.6 \%)$, phenylacetaldehyde $(0.5 \% ; 2.0 \%)$ and phenylacetonitrile $(11.0 \% ; 10.4 \%)$. The comparison with the headspace of all nectars reveals dominant qualitative similarities regarding the major compounds with fluctuation among their percentages (Table 1). Two compounds were found only in the HoS headspace, not in the nectars: pentan-1-ol (1.3\%; 1.3\%) and heptan-2-ol (7.8\%; 3.3\%).

Table 3. The hedaspace composition of C. unshiu honey $(n=12)$ determined by HS-SPME, followed GC-FID and GC-MS analysis.

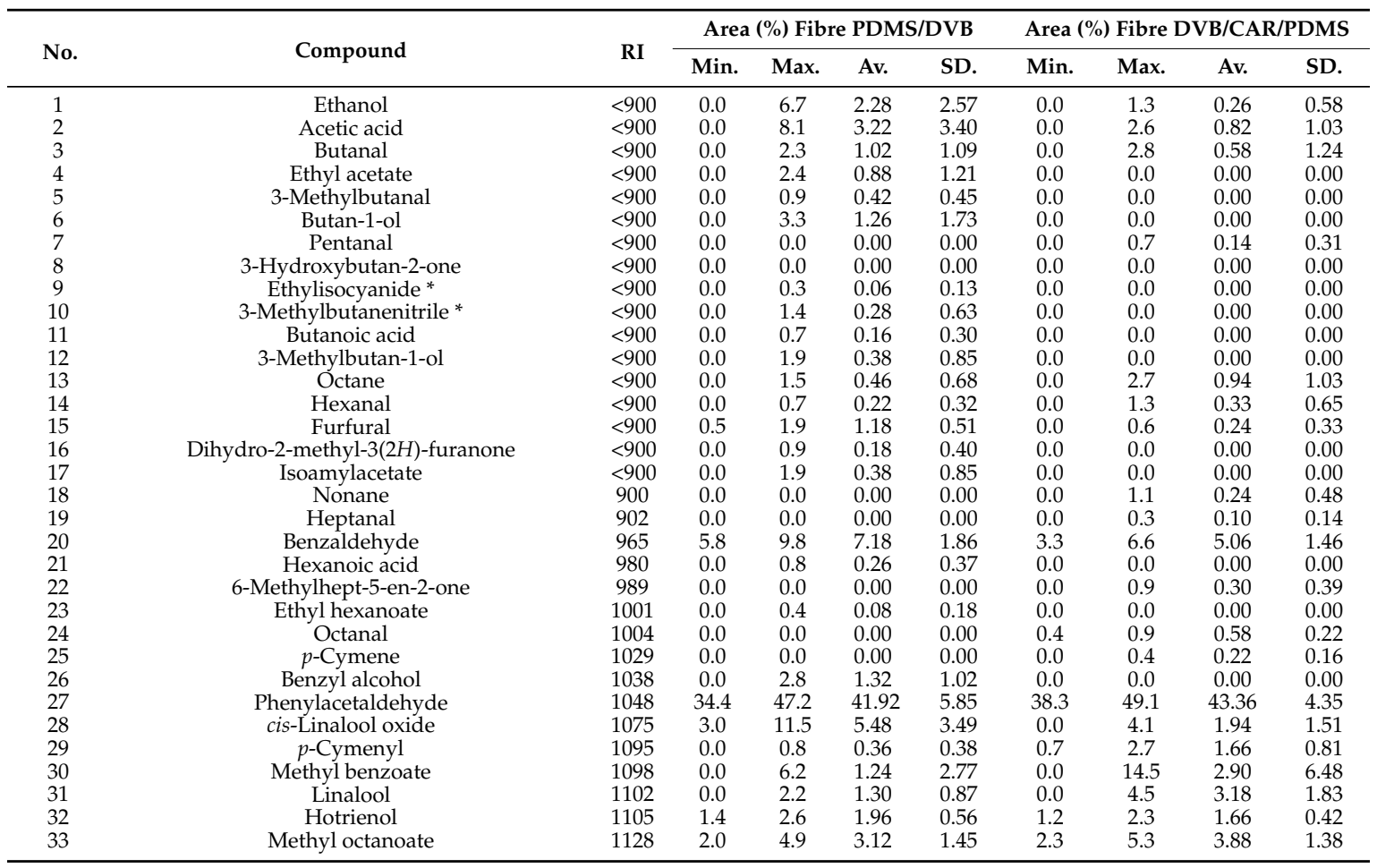


Table 3. Cont.

\begin{tabular}{|c|c|c|c|c|c|c|c|c|c|c|}
\hline \multirow{2}{*}{ No. } & \multirow{2}{*}{ Compound } & \multirow{2}{*}{ RI } & \multicolumn{4}{|c|}{ Area (\%) Fibre PDMS/DVB } & \multicolumn{4}{|c|}{ Area (\%) Fibre DVB/CAR/PDMS } \\
\hline & & & Min. & Max. & Av. & SD. & Min. & Max. & Av. & SD. \\
\hline 34 & Phenylacetonitrile & 1143 & 2.7 & 9.9 & 5.44 & 3.12 & 3.4 & 10.2 & 6.62 & 3.04 \\
\hline 36 & Lilac aldehyde (isomer II) ** & 1178 & 0.0 & 0.5 & 0.10 & 0.22 & 0.0 & 0.8 & 0.16 & 0.36 \\
\hline 37 & Lilac aldehyde (isomer III) ** & 1188 & 0.0 & 0.0 & 0.00 & 0.00 & 0.0 & 0.4 & 0.16 & 0.22 \\
\hline 38 & Octanoic acid & 1194 & 0.0 & 0.0 & 0.00 & 0.00 & 0.0 & 0.4 & 0.12 & 0.18 \\
\hline 39 & Dill ether & 1198 & 0.0 & 0.7 & 0.14 & 0.31 & 0.0 & 0.0 & 0.00 & 0.00 \\
\hline 42 & Methyl nonanoate & 1217 & 0.0 & 1.0 & 0.20 & 0.45 & 0.0 & 0.0 & 0.00 & 0.00 \\
\hline 43 & 8,9-Epoxy- $p$-menth-1-ene * & 1218 & 0.0 & 0.0 & 0.00 & 0.00 & 0.0 & 4.6 & 2.82 & 1.80 \\
\hline 44 & $p$-Meth-9-en-1-al (isomer I) ** & 1221 & 0.0 & 1.1 & 0.22 & 0.49 & 0.0 & 0.0 & 0.00 & 0.00 \\
\hline 45 & $p$-Meth-9-en-1-al (isomer II) ** & 1257 & 0.0 & 0.5 & 0.10 & 0.22 & 0.0 & 0.5 & 0.10 & 0.22 \\
\hline 46 & 4-Methoxybenzaldehyde & 1276 & 0.0 & 0.3 & 0.06 & 0.13 & 0.0 & 0.7 & 0.22 & 0.32 \\
\hline 47 & 3-Methyl-6-(1-methylethyl)-cyclohex-2-en-1-one & 1258 & 0.0 & 0.0 & 0.00 & 0.00 & 0.0 & 1.2 & 0.52 & 0.52 \\
\hline 48 & Nonanoic acid & 1272 & 2.1 & 3.3 & 2.86 & 0.50 & 2.3 & 4.9 & 3.60 & 1.25 \\
\hline
\end{tabular}

Min. = minimal percentage, Max. = maximal percentage, Av. = average percentage, SD. = standard deviation, $\mathrm{RI}=$ retention indices on HP-5MS column, ${ }^{*}=$ tentatively identified, ${ }^{* *}=$ correct isomer is not identified.

Table 4. The results of GC-FID and GC-MS analysis of C. unshiu honey $(n=12)$ ultrasonic solvent extracts.

\begin{tabular}{|c|c|c|c|c|c|c|c|c|c|c|}
\hline \multirow{2}{*}{ No. } & \multirow{2}{*}{ Compound } & \multirow{2}{*}{ RI } & \multicolumn{4}{|c|}{ Area (\%) USE (Pentane/Et ${ }_{2} \mathrm{O}$ 1:2 (v/v)) } & \multicolumn{4}{|c|}{ Area (\%) USE $\left(\mathrm{CH}_{2} \mathrm{Cl}_{2}\right)$} \\
\hline & & & Min. & Max. & Av. & SD. & Min. & Max. & Av. & SD. \\
\hline 1 & Ethylbenzene & $<900$ & 0.1 & 0.8 & 0.24 & 0.31 & 0.0 & 0.1 & 0.03 & 0.05 \\
\hline 2 & 1,3-Dimethylbenzene ** & $<900$ & 0.2 & 3.1 & 0.88 & 1.25 & 0.0 & 0.1 & 0.03 & 0.05 \\
\hline 3 & 14-Dimethylbenzene ** & $<900$ & 0.1 & 0.8 & 0.34 & 0.34 & 0.0 & 0.1 & 0.03 & 0.05 \\
\hline 4 & Benzyl alcohol & 1038 & 0.1 & 0.6 & 0.22 & 0.22 & 0.0 & 0.1 & 0.05 & 0.06 \\
\hline 5 & Phenylacetaldhyde & 1048 & 0.0 & 1.2 & 0.38 & 0.48 & 0.0 & 0.5 & 0.20 & 0.24 \\
\hline 6 & 2-Phenylethanol & 1118 & 0.0 & 0.3 & 0.12 & 0.11 & 0.0 & 0.1 & 0.05 & 0.06 \\
\hline 7 & Benzoic acid & 1166 & 0.1 & 0.3 & 0.14 & 0.09 & 0.0 & 0.2 & 0.08 & 0.10 \\
\hline 8 & Decanal & 1207 & 0.0 & 0.1 & 0.02 & 0.04 & 0.0 & 0.0 & 0.00 & 0.00 \\
\hline 9 & 2,3-Dihydrobenzofuran & 1222 & 0.0 & 0.0 & 0.00 & 0.00 & 0.0 & 0.1 & 0.05 & 0.06 \\
\hline 10 & $\begin{array}{l}\text { Phenylacetic acid } \\
\text { Pall }\end{array}$ & 1262 & 0.1 & 0.3 & 0.18 & 0.08 & 0.1 & 0.2 & 0.15 & 0.06 \\
\hline 11 & $1 H$-Indole & 1295 & 0.1 & 0.3 & 0.14 & 0.09 & 0.1 & 2.6 & 0.90 & 1.16 \\
\hline 12 & 1-Hydroxylinalool ** & 1366 & 0.5 & 6.5 & 2.16 & 2.58 & 0.2 & 2.0 & 1.25 & 0.79 \\
\hline 13 & 4-Hydroxy-2-phenylethanol & 1425 & 0.1 & 0.3 & 0.20 & 0.07 & 0.0 & 0.5 & 0.25 & 0.29 \\
\hline 14 & 1,3 -Dihydro- $2 \mathrm{H}$-indol-2-one & 1471 & 0.2 & 1.7 & 0.74 & 0.60 & 0.1 & 1.3 & 0.53 & 0.57 \\
\hline 15 & Tetradecan-1-ol & 1676 & 0.5 & 1.3 & 0.72 & 0.33 & 0.0 & 0.4 & 0.10 & 0.20 \\
\hline 16 & $1 H$-indole-2,3-dione * & 1698 & 0.0 & 0.1 & 0.02 & 0.04 & 0.0 & 0.9 & 0.45 & 0.37 \\
\hline 17 & Heptadecane & 1700 & 0.0 & 1.0 & 0.30 & 0.42 & 0.0 & 0.0 & 0.00 & 0.00 \\
\hline 18 & Methyl syringate & 1744 & 0.0 & 0.4 & 0.10 & 0.17 & 0.0 & 1.3 & 0.33 & 0.65 \\
\hline 19 & 4-Hydroxy-3,5,6-trimethyl-4-(3-oxo-1-butenyl) & 1796 & 0.2 & 2.0 & 0.84 & 0.81 & 0.2 & 2.4 & 1.53 & 1.04 \\
\hline 20 & Octadecane & 1800 & 0.0 & 0.1 & 0.04 & 0.05 & 0.0 & 0.5 & 0.13 & 0.25 \\
\hline 21 & Caffeine & 1842 & 0.3 & 0.8 & 0.56 & 0.21 & 1.2 & 7.1 & 3.15 & 2.71 \\
\hline 22 & 4-(1-Methyl-1-phenylethyl)phenol & 1858 & 0.0 & 0.0 & 0.00 & 0.00 & 0.0 & 0.2 & 0.05 & 0.10 \\
\hline 23 & Hexadecan-1-ol & 1882 & 5.8 & 15.3 & 10.14 & 3.51 & 2.4 & 5.4 & 3.38 & 1.38 \\
\hline 24 & Nonadecane & 1900 & 0.0 & 1.3 & 0.26 & 0.58 & 0.0 & 0.0 & 0.00 & 0.00 \\
\hline 25 & Hexadecanoic acid & 1963 & 0.5 & 6.6 & 4.02 & 2.88 & 7.3 & 33.8 & 14.90 & 12.71 \\
\hline 26 & Methyl $1 H$-indole-3-acetate & 1980 & 0.0 & 0.2 & 0.04 & 0.09 & 0.0 & 5.6 & 1.95 & 2.62 \\
\hline 27 & Eicosane & 2000 & 0.0 & 0.4 & 0.12 & 0.18 & 0.1 & 0.9 & 0.45 & 0.37 \\
\hline 28 & $\begin{array}{l}\text { 2,3-Dihydro-5,7-dihydroxy-2- } \\
\text { phenyl-4H-1-benzopyran-4-one }\end{array}$ & 2010 & 0.0 & 0.0 & 0.00 & 0.00 & 1.0 & 19.6 & 8.48 & 8.22 \\
\hline 29 & $\begin{array}{c}\text { pnenyy-4H-1-benzopyran-4-one } \\
\text { (Z)-Octadec-9-en-1-ol }\end{array}$ & 2059 & 20.5 & 49.1 & 36.54 & 10.88 & 11.8 & 22.8 & 18.73 & 5.18 \\
\hline 30 & Octadecan-1-ol & 2084 & 4.5 & 11.4 & 7.70 & 2.97 & $\begin{array}{l}11.0 \\
3.8\end{array}$ & 5.4 & 4.80 & 0.70 \\
\hline 31 & Heneicosane & 2100 & 0.0 & 3.7 & 0.78 & 1.63 & 0.0 & 3.0 & 0.75 & 1.50 \\
\hline 32 & (Z)-Octadec-9-enoic acid & 2142 & 0.0 & 0.0 & 0.00 & 0.00 & 0.0 & 15.7 & 5.65 & 7.28 \\
\hline 33 & Docosane & 2200 & 0.2 & 15.7 & 7.34 & 7.73 & 0.0 & 8.5 & 3.30 & 3.76 \\
\hline 34 & (Z)-Tricos-9-ene & 2264 & 0.0 & 1.6 & 0.50 & 0.73 & 0.0 & 2.3 & 0.58 & 1.15 \\
\hline 35 & Tricosane & 2300 & 0.3 & 26.4 & 7.54 & 10.93 & 1.5 & 8.9 & 3.80 & 3.43 \\
\hline 36 & Tetracosane & 2400 & 1.1 & 20.8 & 9.50 & 8.38 & 0.1 & 29.7 & 16.05 & 12.75 \\
\hline
\end{tabular}

Min. = minimal percentage, Max. = maximal percentage, Av. = average percentage, SD. = standard deviation,

$\mathrm{RI}=$ retention indices on HP-5MS column, ${ }^{*}=$ tentatively identified, ${ }^{* *}=$ correct isomer is not identified.

USE extract of HoS contained higher aliphatic compounds, the major ones were (Z)-octadec-9-en-1-ol (45.3\%), octadecan-1-ol (8.6\%), and hexadecan-1-ol (11.6\%), Table 4. These chemical structures are related to the composition of cuticular waxes and less to pheromones, but have been also found in NE (Table 2). Fatty acids and alcohols were previously identified as the major compounds of the solvent organic extract from the sacs of the bees that collected Mentha spp. nectar, and methyl syringate, terpendiol I and vomifoliol were attributed to the plant origin [27]. Other important 
compounds from Table 2 were caffeine (11.5\%), $1 \mathrm{H}$-indole (1.6\%), 1,3-dihydro- $2 \mathrm{H}$-indol-2-one (6.4\%), and methyl anthranilate (1.4\%). USE extracts of HoS and NE were very similar. Only 1-hydroxylinalool appeared (5.4\%) in HoS, which can be indication of the beginning of linalool transformations triggered by the enzymes and continued later in the combs.

\subsection{The Chemical Composition of C. unshiu Honey Headspace, Volatiles and Semi-Volatiles}

On returning to the hive, the content of the honey-sac is regurgitated into the honeycomb and ripened into honey. Under the honeycomb oxidative atmosphere sensitive honey organic compounds can undergo oxidation [28]. There are only a few studies in which the organic extractives of the honey-sac have been correlated with those of the corresponding honey. The comparison of the components of the extracts of Linden honey and honey-sac contents showed that nectar and honey-sac contents contain many aldehydes which were found as corresponding acids in the honey, while the aliphatic compounds, isoprenoids and the alkaloids remained unchanged [28]. In another research, the major identified terpene in the honey-sac was 3,7-dimethylocta-1,5-dien-3,7-diol (terpendiol I) and it was found in Mentha spp. honey solvent extracts, but also can transform to hotrienol, the most abundant compound in the honey headspace [27].

Phenylacetaldehyde was dominant compound $(34.4 \%-47.2 \% ; 38.3 \%-49.1 \%)$ of the C. unshiu honey headspace, followed by benzaldehyde $(5.8 \%-9.8 \% \% ; 3.3 \%-6.6 \%)$. Among other benzene derivatives, abundant was phenylacetonitrile $(2.7 \%-9.9 \% ; 3.4 \%-10.2 \%)$. Phenylacetaldehyde was strikingly more abundant in comparison with the nectar headspace (HS-NE) and the headspace of the honey-sac (HS-HoS), shown in Table 1, indicating its formation during the honey ripening in the hive, since heat was not applied to the samples. This can be generated from phenylalanine either by enzyme catalysis or by Strecker degradation [29]. A high percentage of phenylacetaldehyde was found in the honey headspace of Asphodelus microcarpus Salz. et Viv. [30]. Phenylacetonitrile was present within percentage ranges similar to those seen in the HS-NE and HS-HoS (Table 1), while benzaldehyde percentages were elevated. In addition to phenylacetonitrile, two aliphatic nitriles were detected in several honey samples with minor percentages (Table 3): ethylisocyanide and 3-methylbutanenitrile. Benzaldehyde was found to be the major volatile from the honey of cambara and willow, but also in lemon and orange honey $[17,29]$. Phenylacetonitrile was found in the headspace of dandelion and thyme honeys [31,32].

Linalool was present as a minor constituent $(0.0 \%-2.2 \% ; 0.0 \%-4.5 \%)$ in distinction to HS-NE and HS-HoS. However, an array of linalool derivatives were found, such as cis-linalool oxide $(3.0 \%-11.5 \%$; $0.0 \%-4.1 \%)$, hotrienol $(1.4 \%-2.6 \% ; 1.2 \%-2.3 \%)$, lilac aldehydes, dill ether or $p$-menth-9-en-1-al isomers, not present at all in HS-NE and HS-HoS. They were formed from linalool within the hive conditions. Hotrienol derive either from dehydration of 2,6-dimethylocta-3,7-diene-2,6-diol or from allylic rearrangement and dehydration of 3,7-dimethylocta-1,7-diene-3,6-diol, which can be liberated from the corresponding glucoside or from dehydration of 8-hydroxylinalool [7]. Lilac aldehydes are formed by oxidation of lilac alcohols generated by hydroxylation of linalool to $(E)-8$-hydroxylinalool, and further to $(E)-8$-oxolinalool. Dill ether and $p$-menth-1-ene-9-al isomers and $p$-menth-1-ene-8-ol ( $\alpha$-terpineol) are also derived from $(E)$-8-hydroxylinalool via allylic rearrangement and cyclisation of 8-hydroxygeraniol. Epoxidation of linalool gives 6,7-epoxylinalool, which undergoes further reactions to form linalool oxides and anhydrolinalool oxides, which can further yield lilac alcohols. The formation of linalool oxides and 2,6-dimethylocta-3,7-diene-2,6-diol was probably catalysed by the enzymes secreted by the bees [7].

$1 H$-indole and methyl anthranilate were occasionally present, but not in the headspace of all honey samples, and with markedly lower percentages in comparison to HS-NE and HS-HoS.

Among lower aliphatic compounds of the honey headspace, nonanoic acid was the most abundant $(2.2 \%-3.3 \% ; 2.3 \%-4.9 \%)$, but not found in HS-NE and HS-HoS.

Predominant compounds of the extracts were higher aliphatic compounds, such as (Z)-octadec-9-en-1-ol (20.5\%-49.1\%; 11.8\%-22.8\%), hexadecanoic acid $(0.5 \%-6.6 \% ; 7.3 \%-33.8 \%)$, 
octadecan-1-ol (4.5\%-11.4\%; $3.8 \%-5.4 \%)$ and hexadecan-1-ol (5.8\%-15.3\%; 2.4\%-5.4\%). These compounds (except hexadecanoic acid) were found also in the nectar extracts (E-NE) and the honey-sac extract (E-HoS), but cannot be connected with specific botanical origin since they can be transferred from the comb environment [33]. Similar applies for higher alkanes found only in the honey extracts: tetracosane $(1.1 \%-20.8 \% ; 0.1 \%-29.7 \%)$, tricosane $(0.3 \%-26.4 \%)$, docosane $(0.2 \%-15.7 \% ; 0.0 \%-8.5 \%)$ or heneicosane $(0.0 \%-3.7 \% ; 0.0 \%-3.0 \%)$. Among interesting compounds of the extracts, $1 H$-indole $(0.1 \%-0.3 \% ; 0.1 \%-2.6 \%)$ and 1,3 -dihydro- $2 H$-indol-2-one $(0.2 \%-1.7 \% ; 0.1 \%-1.3 \%)$ can be pointed out, similar to E-NE and E-HoS. Caffeine was also detected in all of the extracts $(0.3 \%-0.8 \% ; 1.2 \%-7.1 \%)$ with lower abundance in comparison to E-NE and E-HoS. In distinction to E-NE and E-HoS, two interesting compounds were present in the honey extracts: 1-hydroxylinalool $(0.5 \%-6.5 \% ; 0.2 \%-2.0 \%)$ and vomifoliol $(0.2 \%-2.0 \%$; $0.2 \%-2.4 \%$ ). 1-Hydroxylinalool, previously identified in E-HoS, is a good indicator of linalool transformations providing linalool derivatives found only in the honey headspace. Norisoprenoid vomifoliol was not found in E-NE and E-HoS and, therefore, could be transferred from the comb environment. Pinocembrin (5,7-dihydroxy-2-phenyl-2,3-dihydro-4H-chromen-4-one) was found only in $\mathrm{CH}_{2} \mathrm{Cl}_{2}$ extracts. It is a flavanone, containing the nucleus of hesperetin (2,3-dihydro-5,7-dihydroxy-2-(3-hydroxy-4-methoxyphenyl)-4H-1-benzopyran-4-one) that was found in Citrus honeys [13]. Due to the high molecular mass of pinocembrin, GC-MS is not a good method for its quantification (as for other flavanones). In addition, it could originate from propolis and, therefore, it is not commented in detail.

In comparison with other Citrus honey VOCs, several similarities can be pointed out. Namely, the suitability of methyl anthranilate, originating from the plant, as the chemical marker of Citrus honey types has been already found [34]. Along with the detection of methyl anthranilate, more than 60 different VOCs were also reported [11,12,17] in Citrus honey types. Similar to the present research, benzaldehyde, phenylacetaldehyde, and linalool derivatives (e.g., linalool oxides, lilac aldehyde isomers, or $p$-menth-1-en-9-al) were found among important Citrus honey headspace compounds. Caffeine was also previously found as a characteristic compound of Citrus honey [35]. However, despite previous studies on Citrus honeys, few particular compounds were present in C. Unshiu honey not already mentioned in other Citrus honeys, such as $1 H$-indole, 1,3-dihydro-2H-indol-2-one, and phenylacetonitrile.

\section{Materials and Methods}

\subsection{The Nectar, Honey-Sac and Honey Samples}

The nectars $(1.5 \mathrm{~mL})$ from the varieties Zorica, Chahara, Kawano Wase, and Okitsu were collected with microcapillary glass tubes from trees growing in the Neretva valley, Opuzen area, Croatia, in 2016. In the study area $90 \%$ of Citrus orchards were Satsuma mandarins (Citrus unshiu Marc.), while others were clementine (C. clementina Hort. ex Tan.), sweet orange (C. sinensis), grapefruit (C. paradisi), and lemon (C. limon).

During C. unshiu honey flow, a part of the returning foragers were collected. The bees were frozen in the field by liquid nitrogen and were stored in a deep-freezer until their honey-sac contents were investigated. After thawing, the abdomen of 100 bees was dissected by peeling off the tergit with forceps in order to expose the honey sac. The honey sacs were removed and frozen. After freezing, the entire content of the honey-sacs was pooled and put in a glass vial $(5 \mathrm{~mL})$ at $4{ }^{\circ} \mathrm{C}$ until the volatiles were isolated.

Twelve C. unshiu honey samples were investigated. The combs from specially prepared colonies, which were formed from $2 \mathrm{~kg}$ of packaged bees on wax foundation, were placed in the area of predominantly C. unshiu trees growing in the Neretva valley, Opuzen area, Croatia, but the samples were also collected from local beekeepers. All of the samples were stored in hermetically closed glass bottles at $4{ }^{\circ} \mathrm{C}$ until the volatiles were isolated. Melissopalynological analysis was performed 
by the method recommended by the International Commission for Bee Botany [36]. Microscopical examination was carried out on a Hund h 500 (Wetzlar, Germany) light microscope attached to a digital camera (Motic m 1000, Motic Deutschland GmbH, Wetzlar, Germany) and coupled to an image analysis system (Motic Images Plus software, Motic Deutschland $\mathrm{GmbH}$ ) for morphometry of pollen grains.

\subsection{Headspace Solid-Phase Microextraction (HS-SPME)}

The headspace extraction was performed using a manual SPME holder using two fibres: divinylbenzene/carboxene/polydimethylsiloxane (DVB/CAR/PDMS) and polydimethylsiloxane/divinylbenzene (PDMS/DVB) obtained from Supelco Co. (Bellefonte, PA, USA). The fibres were conditioned prior to use according to the instructions by Supelco Co. For HS-SPME, the nectars $(1 \mathrm{~mL})$ were placed separately in $5 \mathrm{~mL}$ glass vials and hermetically sealed with PTFE/silicone septa. The content of honey-sacs was put as described above in $5 \mathrm{~mL}$ glass vial and hermetically closed with PTFE/silicone septa. The honey/saturated water solution $(5 \mathrm{~mL}, 1: 1(v / v)$; saturated with $\mathrm{NaCl})$ of each honey sample was placed in a $15 \mathrm{~mL}$ glass vial and hermetically sealed with PTFE/silicone septa.

The vials were maintained in a water bath at $60^{\circ} \mathrm{C}$ during equilibration (15 min) and HS-SPME (45 $\mathrm{min}$ ) and were partially submerged so that the liquid phase of the sample was below the water level. All of the experiments were performed under constant stirring (1000 rpm) with a magnetic stirrer. After sampling, the SPME fibre was withdrawn into the needle, removed from the vial, and inserted into the injector $\left(250^{\circ} \mathrm{C}\right)$ of the GC-FID and GC-MS for 6 min where the extracted volatiles were thermally desorbed directly to the GC column.

\subsection{Ultrasonic Solvent Extraction (USE)}

Ultrasound-assisted solvent extraction (USE) was performed in an ultrasound cleaning bath (Clean 01, MRC Scientific Instruments, London, UK) by the indirect sonication mode at a frequency of $37 \mathrm{kHz}$ at $25 \pm 3{ }^{\circ} \mathrm{C}$. Two solvents were separately used for USE: a mixture of pentane/diethyl ether, $1: 2(v / v)$ and dichloromethane.

The nectars $(0.5 \mathrm{~mL})$ were separately dissolved in flasks $(5 \mathrm{~mL})$ in $0.5 \mathrm{~mL}$ distilled water, $\mathrm{MgSO}_{4}$ $(0.05 \mathrm{~g})$ was added and the sample was vortexed $(5 \mathrm{~min})$. Dichloromethane $(1 \mathrm{~mL})$ was used for USE of dissolved nectars.

The content of honey-sacs was dissolved in distilled water $(0.5 \mathrm{~mL})$ in $5 \mathrm{~mL}$ flask, $\mathrm{MgSO}_{4}$ $(0.03 \mathrm{mg})$ was added, and the sample was vortexed $(5 \mathrm{~min})$. USE was performed using dichloromethane $(1.5 \mathrm{~mL})$. Forty grams of each C. unshiu honey sample was dissolved in distilled water $(22 \mathrm{~mL})$ in a $100-\mathrm{mL}$ flask. Magnesium sulphate $(1.5 \mathrm{~g})$ was added and each sample was vortexed (10 $\mathrm{min})$. Both solvents $(20 \mathrm{~mL})$ were separately used for USE of the honey samples.

The sonication was maintained for $30 \mathrm{~min}$. After sonication, the organic layer was separated by centrifugation and filtered over anhydrous $\mathrm{MgSO}_{4}$. The aqueous layer was returned to the flask and another batch of the same extraction solvent was added and extracted by ultrasound for $30 \mathrm{~min}$. The organic layer was separated in the same way as the previous one and filtered over anhydrous $\mathrm{MgSO}_{4}$, and the aqueous layer was sonicated a third time for $30 \mathrm{~min}$ with another batch of the extraction solvent. Combined organic extracts were concentrated to $0.2 \mathrm{~mL}$ by distillation with a Vigreaux column, and $1 \mu \mathrm{L}$ was used for GC-FID and GC-MS analyses.

\subsection{GC-FID and GC-MS Analyses}

The GC-FID analyses were carried out with an Agilent Technologies (Palo Alto, CA, USA) gas chromatograph model 7890A equipped with a flame ionization detector (FID) and a HP-5MS capillary column (5\% phenyl-methylpolysiloxane, Agilent J and W). The GC conditions were similar to those described previously [24]. In brief, the oven temp. was programmed isothermal at $70{ }^{\circ} \mathrm{C}$ for $2 \mathrm{~min}$, increasing from $70-200^{\circ} \mathrm{C}$ at $3^{\circ} \mathrm{C} \cdot \mathrm{min}^{-1}$, and held isothermally at $200^{\circ}$ for $15 \mathrm{~min}$; carrier gas, He $\left(1.0 \mathrm{~mL} \cdot \mathrm{min}^{-1}\right)$. 
The GC-MS analyses were performed using an Agilent Technologies (Palo Alto, CA, USA) gas chromatograph model 7820A equipped with a mass selective detector (MSD) model 5977E (Agilent Technologies) and a HP-5MS capillary column, under the same conditions as described for the GC-FID analysis. The MSD (EI mode) was operated at $70 \mathrm{eV}$, and the mass range was $30-300 \mathrm{amu}$, as previously reported [24].

The identification of the volatile constituents was based on the comparison of their retention indices (RI), determined relative to the retention times of a homologous series of $n$-alkanes $\left(C_{9}-C_{25}\right)$, with those reported in the literature [25] and their mass spectra with authentic compounds available in our laboratories or those listed in Wiley 9 (Wiley, New York, NY, USA) and NIST 14 (D-Gaithersburg) mass spectral libraries [25]. The percentage composition of the samples was computed from the GC peak areas using the normalization method (without correction factors). The average component percentages in the tables were calculated from duplicate GC-FID and GC-MS analyses.

\section{Conclusions}

Applied HS-SPME/GC-MS/FID and USE/GC-MS/FID methodologies of monitoring nectar/honey-sac/honey pathways of the headspace, volatiles, and semi-volatiles was successful and complementary for the characterisation of $C$. unshiu honey. The major headspace compounds from all nectar varieties were linalool, $\alpha$-terpineol, $1 H$-indole, methyl anthranilate, and phenylacetonitrile. Corresponding extracts contained, among others, $1 H$-indole, methyl anthranilate, 1,3-dihydro- $2 \mathrm{H}$-indol-2-one and caffeine. The major headspace compounds of the honey-sac were linalool, $\alpha$-terpineol, 1,8-cineole, $1 H$-indole, methyl anthranilate, and cis-jasmone. Characteristic compounds from related extract were caffeine, $1 \mathrm{H}$-indole, 1,3-dihydro- $\mathrm{H}$-indol-2-one, methyl anthranilate, and phenylacetaldehyde. However, the honey headspace composition was significantly different in comparison to the nectars and the honey-sac content with respect to phenylacetaldehyde and linalool derivatives' abundances that appeared as the consequence of the hive conditions and the bee enzymes' activity. All extracts contained higher aliphatic compounds as the major constituents not useful for botanical origin determination, since they can originate from the comb environment. C. unshiu honey traceability is determined by the following chemical markers: phenylacetaldehyde, phenylacetonitrile, linalool, and its derivatives (from the headspace), as well as $1 H$-indole, 1,3-dihydro- $2 H$-indol-2-one, and caffeine (from the extracts). $1 H$-Indole, 1,3-dihydro- $2 H$-indol-2-one, and phenylacetonitrile were found as particular compounds of $C$. unshiu honey, not pointed out in previous studies of other Citrus honey types.

Acknowledgments: This research has been fully supported by the Croatian Science Foundation under the project (HRZZ-IP-11-2013-8547 "Research of natural products and flavours: chemical fingerprinting and unlocking the potential").

Author Contributions: I.J., S.P., L.S. and D.B. designed the experiments. S.P., Z.M., L.S. and M.Z. performed the experiments. S.P., Z.M., M.Z., C.I.G.T. and I.J. analyzed the data. All the authors discussed and planned the paper. I.J. and C.I.G.T. drafted the manuscript.

Conflicts of Interest: The authors declare no conflict of interest.

\section{References}

1. Popović, L.; Vego, D. Mandarin varieties in Opuzen. Polmol. Croat. 2010, 16, 89-107.

2. Ohe, W.; Persano-Oddo, L.; Piana, M.L.; Morlot, M.; Martin, P. Harmonized methods of melissopalynology. Apidologie 2004, 35, 18-25.

3. Serra-Bonvehí, J. Characterization of citrus honey (Citrus spp.) produced in Spain. J. Agric. Food Chem. 1995, 43, 2053-2057. [CrossRef]

4. Rodriguez, I.; Salud, S.; Hortensia, G.; Luis, U.J.; Jodral, M. Characterisation of Sierra Morena citrus blossom honey (Citrus sp.). Int. J. Food Sci. Technol. 2010, 45, 2008-2015. [CrossRef]

5. Kaškonienè, V.; Venskutonis, P.R. Floral markers in honey of various botanical and geographic origins: A review. Compr. Rev. Food Sci. Food Saf. 2010, 9, 620-634. [CrossRef] 
6. Cuevas-Glory, L.F.; Pino, J.A.; Santiago, L.S.; Sauri-Duch, E. A review of volatile analytical methods for determining the botanical origin of honey. Food Chem. 2007, 103, 1032-1043. [CrossRef]

7. Jerković, I.; Kuś, P.M. Terpenes in honey: Occurrence, origin and their role as chemical biomarkers. RSC Adv. 2014, 4, 31710-31728. [CrossRef]

8. Amtmann, M. The chemical relationship between the scent features of goldenrod (Solidago canadensis L.) flower and its unifloral honey. J. Food Compos. Anal. 2010, 23, 122-129. [CrossRef]

9. Alissandrakis, E.; Daferera, D.; Tarantilis, P.A.; Polissiou, M.; Harizanis, P.C. Ultrasound-assisted extraction of volatile compounds from citrus flowers and citrus honey. Food Chem. 2003, 82, 575-582. [CrossRef]

10. Alissandrakis, E.; Tarantilis, P.A.; Harizanis, P.C.; Polissiou, M. Evaluation of four isolation techniques for honey aroma compounds. J. Sci. Food Agric. 2005, 85, 91-97. [CrossRef]

11. Alissandrakis, E.; Tarantilis, P.A.; Harizanis, P.C.; Polissiou, M. Aroma investigation of unifloral Greek citrus honey using solid-phase microextraction coupled to gas chromatographic-mass spectrometric analysis. Food Chem. 2007, 100, 396-404. [CrossRef]

12. Castro-Vazquez, L.; Diaz-Maroto, M.C.; Pérez-Coello, M.S. Aroma composition and new chemical markers of Spanish citrus honeys. Food Chem. 2007, 103, 601-606. [CrossRef]

13. Escriche, I.; Kadar, M.; Juan-Borrás, M.; Domenech, E. Using flavonoids, phenolic compounds and headspace volatile profile for botanical authentication of lemon and orange honeys. Food Res. Int. 2011, 44, 1504-1513. [CrossRef]

14. Serra-Bonvehí, J. Determinación de antranilato de metilo en la miel de cítricos (Citrus sp.) del Levante Español y su influencia en la actividad diastásica de la miel. Alimentaria 1988, 197, 37-40. (In Spanish)

15. Verzera, A.; Tripodi, G.; Condurso, C.; Dima, G.; Marra, A. Chiral volatile compounds for the determination of orange honey authenticity. Food Control 2014, 39, 237-243. [CrossRef]

16. Kadar, M.; Juan-Borrás, M.; Carot, J.M.; Domenech, E.; Escriche, I. Volatile fraction composition and physicochemical parameters as tools for the differentiation of lemon blossom honey and orange blossom honey. J. Sci. Food Agric. 2011, 91, 2768-2776. [CrossRef] [PubMed]

17. Papotti, G.; Bertelli, D.; Plessi, M. Use of HS-SPME-GC-MS for the classification of Italian lemon, orange and citrus spp. honeys. Int. J. Food Sci. Technol. 2012, 47, 2352-2358. [CrossRef]

18. Kretschmar, J.A.; Baumann, T.W. Caffeine in Citrus flowers. Phytochemistry 1999, 52, 19-23. [CrossRef]

19. Mravak, A.; Bubalo, D.; Bujan, M.; Prđun, S.; Svečnjak, L. Physico-chemical properties of mandarin honey from Dubrovačko-neretvanska County. In Proceedings of the 49th Croatian and 9th International Symposium on Agriculture, Faculty of Agriculture, Valamar Lacroma Dubrovnik, Croatia, 16-21 February 2014; University of Josip Juraj Strossmayer: Osijek, Croatia, 2014; pp. 499-503.

20. Radwanski, E.R.; Last, R.L. Tryptophan biosynthesis and metabolism: Biochemical and molecular genetics. Plant Cell 1995, 7, 921-934. [CrossRef] [PubMed]

21. Vick, B.A.; Zimmerman, D.C. Biosynthesis of jasmonic acid by several plant species. Plant Physiol. 1984, 75, 458-461. [CrossRef] [PubMed]

22. Legras, J.L.; Chuzel, G.; Arnaud, A.; Galzy, P. Natural nitriles and their metabolism. J. Microbiol. Biotechnol. 1990, 6, 83-108. [CrossRef] [PubMed]

23. Akhaja, T.N.; Raval, J.P. 1,3-Dihydro-2H-indol-2-ones derivatives: Design, synthesis, in vitro antibacterial, antifungal and antitubercular study. Eur. J. Med. Chem. 2011, 46, 5573-5579. [CrossRef] [PubMed]

24. Koshiro, Y.; Zheng, X.-Q.; Wang, M.-L.; Nagai, C.; Ashihara, H. Changes in content and biosynthetic activity of caffeine and trigonelline during growth and ripening of Coffea arabica and Coffea canephora fruits. Plant Sci. 2006, 171, 242-250. [CrossRef]

25. Tao, N.-G.; Liu, Y.-J.; Zhang, J.-H.; Zeng, H.Y.; Tang, Y.-F.; Zhang, M.-L. Chemical composition of essential oil from the peel of Satsuma mandarin. Afr. J. Biotechnol. 2008, 7, 1261-1264.

26. Kim, M.J.; Yang, K.W.; Kim, S.S.; Park, S.M.; Park, K.J.; Kim, K.S.; Choi, Y.H.; Cho, K.K.; Hyun, C.G. Chemical composition and anti-inflammation activity of essential oils from Citrus unshiu flower. Nat. Prod. Commun. 2014, 9, 727-730. [PubMed]

27. Jerković, I.; Hegić, G.; Marijanović, Z.; Bubalo, D. Organic Extractives from Mentha spp. honey and the bee-stomach: Methyl syringate, vomifoliol, terpenediol I, hotrienol and other compounds. Molecules 2010, 15, 2911-2924. [CrossRef] [PubMed] 
28. Naef, R.; Jaquier, A.; Velluz, A.; Bachofen, B. From the linden flower to linden honey-Volatile constituents of linden nectar, the extract of bee-stomach and ripe honey. Chem. Biodivers. 2004, 1, 1870-1879. [CrossRef] [PubMed]

29. Jerković, I. Volatile benzene derivatives as honey biomarkers. Synlett 2013, 24, 2331-2334. [CrossRef]

30. Jerković, I.; Tuberoso, C.I.G.; Kasum, A.; Marijanović, Z. Volatile Compounds of Asphodelus microcarpus Salzm. et Viv. honey obtained by HS-SPME and USE analyzed by GC/MS. Chem. Biodivers. 2011, 8, 587-598. [CrossRef] [PubMed]

31. Jerković, I.; Marijanović, Z.; Kranjac, M.; Radonić, A. Comparison of different methodologies for detailed screening of Taraxacum officinale honey volatiles. Nat. Prod. Commun. 2015, 10, 357-360. [PubMed]

32. Alissandrakis, E.; Tarantilis, P.A.; Harizanis, P.C.; Polissiou, M. Comparison of the volatile composition in thyme honeys from several origins in Greece. J. Agric. Food Chem. 2007, 55, 8152-8157. [CrossRef] [PubMed]

33. Jerković, I.; Marijanović, Z.; Ljubičić, I.; Gugić, M. Contribution of the bees and combs to honey volatiles: Blank-trial probe for chemical profiling of honey biodiversity. Chem. Biodivers. 2010, 7, 1217-1230. [CrossRef] [PubMed]

34. Bertelli, D.; Papotti, G.; Lolli, M.; Sabatini, A.G.; Plessi, M. Development o fan HS-SPME-GC method to determine the methyl anthranilate in Citrus honeys. Food Chem. 2008, 108, 297-303. [CrossRef]

35. Trova, C.; Cossa, G.; Gandolfo, G. Occurrence of caffeine in citrus honey. Ind. Aliment. Italy 1994, 33, $403-405$.

36. Louveaux, J.; Maurizio, A.; Vorwohl, G. Methods of melissopalynology. Bee World 1978, 59, $139-153$. [CrossRef]

Sample Availability: The honey samples are available from the authors for limited time.

(C) 2016 by the authors; licensee MDPI, Basel, Switzerland. This article is an open access article distributed under the terms and conditions of the Creative Commons Attribution (CC-BY) license (http://creativecommons.org/licenses/by/4.0/). 